\title{
Comparison between Three Radioisotope Methods for Measuring Iron Absorption
}

\author{
J. A. LUNN,* M.B., CH.B., M.R.C.P.ED.; JOHN RICHMOND, † M.D., F.R.C.P.ED., M.R.C.P. \\ J. D. SIMPSON,‡ PH.D., B.SC. ; JOAN D. LEASK,§ B.SC. ; PETER TOTHILL,\| PH.D., B.SC., F.INST.P.
}

Brit. med. F., 1967, 3, 331-333

The present methods for determining iron absorption from the alimentary tract depend on the measurement by radioisotope techniques of iron retained in the body after oral administration. They vary in convenience and complexity, and sometimes require assumptions about iron metabolism for their interpretation.

The first, the "faecal recovery" method, was introduced by Dubach et al. (1948). In this method after a dose of iron-59 has been given by mouth the patient's stools are collected for several days until the excretion of radioactivity has stopped. The most important criticism of the faecal method is the difficulty of ensuring absolutely complete stool collections even from the most intelligent patients and in the best hospital circumstances.

The second, the "double isotope method" first described by Saylor and Finch (1953), makes use of two isotopes of iron, iron-55 and iron-59, which can be measured separately because of the different energies of their radiation. One isotope is given by mouth (iron-59) and simultaneously the other (iron-55) is bound to the patient's plasma protein and injected intravenously. After a suitable interval the ratio of the two isotopes in a blood sample gives a measure of absorption. It is necessary to assume that absorbed iron and parenterally administered iron are handled by the body in exactly the same way through the whole spectrum of iron disorder from iron deficiency to iron overload. Moreover, the separation of iron-59 and iron-55 demands very careful preparation and concentration of samples and complicated counting equipment.

The third, the "whole-body-counting" technique, has been applied by several workers (Price et al., 1961, 1962 ; van Hoek and Conrad, 1961 ; Callender et al., 1966). In this method iron-59 is given by mouth, and shortly afterwards the amount given is determined by external whole-body counting of radioactivity. After 10 to 14 days, when unabsorbed iron has been excreted, the amount of iron retained is determined by a further external whole-body measurement. Of the three methcds this can be seen to be much the most convenient for the doctor and the patient. However, it is necessary to consider the possible change of efficiency of counting between the first and the last measurement. In the first, the " $100 \%$ measurement," the iron is mainly in the alimentary tract, but in the second there might be considerable variation in its distribution in the body, being mainly in the circulating blood in a patient with severe iron deficiency or mainly in the body stores in a patient with refractory anaemia. The whole-body counters employed for this type of study have usually been expensive instruments of high sensitivity and low background, designed to measure levels of natural radioactivity and small burdens of accidental contamination.

These three main radioisotope measurements of iron absorption have been compared simultaneously in a series of patients. No attempt has been made to evaluate the amount of iron absorption in relation to other aspects of iron metabolism, but rather to see what correlation existed between the three methods over a range of haemoglobin level, serum iron, and stainable marrow iron. The main purpose of the present study was to assess a simple and inexpensive apparatus of low but adequate sensitivity for whole-body counting.

\section{Material and Methods}

Iron absorption was measured in 17 patients. They were inpatients in the Royal Infirmary, Edinburgh, and at the time of the study they all had normal bowel function and none showed occult bleeding from the alimentary tract. The patients were in wards where collection of excreta is standard practice for metabolic studies, and the need to be most careful in the complete collection of stools was emphasized to the patients and nursing staff for this particular investigation.

Routine examination of peripheral blood was by methods described by Dacie and Lewis (1963). Serum iron levels and total iron-binding capacity were determined as described by Ramsay (1957). The iron content of sternal marrow aspirate was assessed by a staining technique ; the method is given by Richmond et al. (1956). The amount of iron has been recorded as absent $(\mathrm{O})$ or present in the range one plus to three plus $(t$ to +++$)$. During each study all stools collected were examined for blood by the Haematest method.

\section{Measurements of Iron Absorption}

The first five patients (Cases 1-5) were given $10 \mu \mathrm{Ci}$ of iron-59 orally in the form of ferric chloride (specific activity in the range $3-15 \mu \mathrm{Ci} / \mu \mathrm{g}$.) in a standard breakfast (PirzioBiroli ct al., 1958) containing $7.5 \mathrm{mg}$. of food iron. The remaining 12 (Cases 6-17) received the same amount of iron-59 in the fasting state, together with $10 \mathrm{mg}$. of carrier iron and $50 \mathrm{mg}$. of ascorbic acid. The conditions of administration of iron were changed to produce a wider range in the amount of iron absorbed for the purposes of comparison between the methods.

Iron-55 (specific activity in the range $1-4 \mu \mathrm{Ci} / \mu \mathrm{g}$.) was incubated with the patient's plasma or donor plasma as described by Veall and Vetter (1958), and 60 to 90 minutes after the iron-59 had been taken orally iron-55-labelled plasma containing approximately $20 \mu \mathrm{Ci}$ of iron-55 was injected intravenously.

\section{Faecal Recovery Method}

Measurements of stool radioactivity were made in a counter consisting of a ring of Geiger-Müller tubes. Some stool samples were also assayed with a scintillation counter and good agreement was obtained.

\footnotetext{
* Now Bahamas Government Medical Officer. Formerly Bahamas Government Fellow.

+ Senior Lecturer, Department of Medicine.

¥ Senior Physicist, Department of Medical Physics.

\$ Physicist, Department of Medical Physics

rincipal Physicist, Department of Medical Physics.

Royal Infirmary and University of Edinburgh.
} 


\section{Double Isotope Method}

Blood samples taken at intervals of three to four days and on the same day as the final whole-body measurements were used to determine the ratio between the orally and intravenously administered isotopes. Iron was extracted from the washed red cells (W. N. M. Ramsay et al., to be published) and electroplated on copper discs for counting.

Isotope separation was achieved by the use of two counters. Firstly, the radioactivity of iron-55 was measured by a xenonfilled proportional counter fitted with a beryllium window (Twentieth Century Electronics Ltd., Type PX 130/Xe), which largely absorbs the iron-59 $\beta$-rays but admits a reasonable proportion of the low energy $x$ rays from the iron-55. Pulse height analysis enabled the iron-5s to be counted with an estimated efficiency of $6 \%$ and only $0.2 \%$ efficiency for iron- 59 ; the background count rate was in the range of 0.3 to 0.7 count per second.

The radioactivity of iron-59 was then measured with an end-window Geiger-Müller counter in an anti-coincidence shield (Panax type LC/5). A platinum filter $0.015 \mathrm{~mm}$. thick reduced the effect of the $x$ rays of iron-55 to give counting efficiencies of $5.3 \%$ for iron-59 and $0.001 \%$ for iron-55. The background count rate wás approximately 0.04 count per second.

The absorption of orally administered iron-59 was then calculated as follows:

$\begin{aligned} & \% \text { absorption }= \\ & { }^{s 0} \mathrm{Fe} \text { activity in blood } \\ & \text { "Fe activity administered orally }\end{aligned} \times \frac{{ }^{s s} \mathrm{Fe} \text { activity administered i.v. }}{{ }^{5 s} \mathrm{Fe} \text { activity in blood }} \times 100$

To reduce statistical errors to a minimum long countingtimes were necessary with both techniques. With the proportional counter, counting for 1,000 seconds gave approximately 10,000 counts, while counting for about 60 minutes was necessary to achieve a similar number of counts with the endwindow counter. A separate standard for each isotope was prepared by adding known amounts of radioactivity to a sample of haemolysed red cells taken from the subject before the test. The standard red cells were then digested and electroplated in the same way as the blood samples.

The accuracy of the measurement depended on the similarity of recovery of radioactive iron for each standard. The quantitative recovery of added iron is easier than that of haemoglobin iron, and this consistency was checked in supplementary experiments.

Isotopic contamination of the solutions administered was found to be negligible.

\section{Whole-body Counting Method}

Whole-body iron-59 radioactivity was estimated with a single sodium iodide crystal, $12.5 \mathrm{~cm}$. in diameter and $9 \mathrm{~cm}$. in depth. The background count rate was reduced by means of a $2.5-\mathrm{cm}$. thick lead shield. This consisted of a plate $30 \mathrm{~cm}$. long and $27 \mathrm{~cm}$. wide, through which the crystal protruded, and sides $16 \mathrm{~cm}$. high, forming an inverted U-shape. The shield was designed to accept radiation from the whole body without interference and to provide the maximum reduction in background count rate for a given amount of lead. At the energies used with the iron-59 studies the background count rate was approximately halved.

Measurements were made under integral bias conditions above $1 \mathrm{MeV}$ to include both the 1.1 and $1.3 \mathrm{MeV}$ photopeaks of iron-59; this gave a background count rate of approximately 50 counts per second. Counting was performed in two ways: firstly, with the patient in a sitting position in a reclining chair, and, secondly, with the counter placed at different peints over the patient lying on a horizontal couch.
Measurements over the couch were made with a crystal-tocouch distance of $50 \mathrm{~cm}$. and with the crystal vertically above positions 25,75 , and $125 \mathrm{~cm}$. from the top of the head in each case. Counts were repeated in both the supine and the prone positions with the arms held by the sides. The sum of the six counts was then used as an estimate of the total body radioactivity. After a dose of $9 \mu \mathrm{Ci}$ the mean count rate in these six positions was approximately 360 counts per second, and a total patient counting-time of 600 seconds was used.

Only one 200-second count was required when using the chair geometry, in which the subject reclined with the chest at about $17 \mathrm{~cm}$. from the nearest part of the crystal and with most of the body, except the head and the lower parts of the legs, positioned roughly in a $40-\mathrm{cm}$. arc around the centre of the crystal. A corresponding count in this arrangement after a $9 \mu \mathrm{Ci}$ dose gave approximately 650 counts per second.

The initial count on each patient was made four hours after the administration of iron-59, and this result was taken as the $100 \%$ retention value. The final absorption was estimated by re-counting between 14 and 20 days after the initial count, at which time the retention has reached a coristant level (Schiffer et al., 1964); this observation was verified on several patients by making serial measurements. To allow for any variation in counter sensitivity, a standard iron-59 source in a 5-litre polyethylene container was counted before and after each set of measurements. As the patient himself may modify the background count rate a count was made with him in position before the administration of the isotope, so that subsequent background measurements could be corrected for this.

The main advantage of the couch geometry is that it minimizes the effects of isotope distribution in the body on the efficiency of counting. These effects were studied by measuring the response of the counter to a small source as it was moved in different positions in a tank of water $20 \mathrm{~cm}$. deep. Results showed that the effect of distance of the source from the crystal could be almost eliminated by counting from both sides of the tank and adding the two count rates. Allowance was made for the effect of isotope distribution in the patient by counting in both the prone and the supine positions.

\section{Results}

The main haematological data and the estimation of iron absorption obtained by the three methods in each of the patients are summarized in the Table.

\begin{tabular}{|c|c|c|c|c|c|c|c|c|c|}
\hline \multirow[b]{3}{*}{$\begin{array}{l}\dot{0} \\
z \\
\ddot{y} \\
\ddot{U}\end{array}$} & \multirow{3}{*}{ 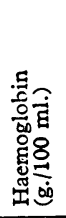 } & \multirow{3}{*}{ 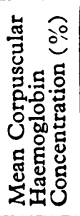 } & \multirow{3}{*}{ 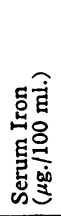 } & \multirow{3}{*}{ 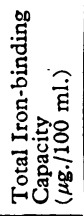 } & \multirow{3}{*}{ 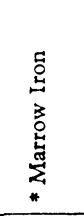 } & \multicolumn{4}{|c|}{$\begin{array}{c}\text { Iron Absorption } \\
\text { Per Cent. Administered }\end{array}$} \\
\hline & & & & & & \multirow[b]{2}{*}{ 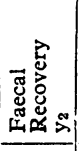 } & \multicolumn{2}{|c|}{$\begin{array}{l}\text { Whole Body } \\
\text { Counting }\end{array}$} & \multirow[b]{2}{*}{ 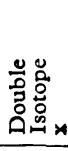 } \\
\hline & & & & & & & 总 & 忞 & \\
\hline $\begin{array}{r}1 \\
2 \\
3 \\
4 \\
5 \\
6 \\
7 \\
8 \\
9 \\
10 \\
11 \\
12 \\
13 \\
14 \\
15 \\
16 \\
17\end{array}$ & $\begin{array}{r}14.6 \\
7.1 \\
5.3 \\
10.6 \\
5.0 \\
14.2 \\
14.2 \\
7.0 \\
14.6 \\
7.3 \\
6.9 \\
10.8 \\
5.1 \\
9.9 \\
6.1 \\
8.6 \\
8.3\end{array}$ & $\begin{array}{c}35.0 \\
33.4 \\
31.6 \\
31.8 \\
25.1 \\
= \\
28.9 \\
33.0 \\
25.0 \\
25.3 \\
31.0 \\
30.5 \\
33.5 \\
24.8 \\
27.0 \\
31.8\end{array}$ & $\begin{array}{r}115 \\
267 \\
85 \\
78 \\
5 \\
60 \\
-700 \\
\frac{200}{50} \\
44 \\
39 \\
95 \\
27 \\
28 \\
160\end{array}$ & $\begin{array}{l}\bar{z} \\
212 \\
345 \\
134 \\
\overline{246} \\
\overline{594} \\
582 \\
522 \\
360 \\
412 \\
307 \\
343\end{array}$ & $\begin{array}{c}++ \\
++ \\
+ \\
+ \\
0 \\
= \\
+ \\
+ \\
0 \\
0 \\
0 \\
++ \\
0 \\
0 \\
0 \\
+\end{array}$ & $\begin{array}{l}22 \\
12 \\
10 \\
28 \\
25 \\
82 \\
39 \\
73 \\
50 \\
97 \\
91 \\
91 \\
44 \\
37 \\
57 \\
85 \\
34\end{array}$ & $\begin{array}{c}0 \\
0 \\
0 \\
1 \\
13 \\
78 \\
25 \\
65 \\
12 \\
93 \\
85 \\
74 \\
31 \\
15 \\
43 \\
\frac{13}{13}\end{array}$ & $\begin{array}{r}0 \\
0 \\
0 \\
1 \\
9 \\
96 \\
27 \\
66 \\
10 \\
117 \\
109 \\
90 \\
32 \\
17 \\
44 \\
87 \\
15\end{array}$ & $\begin{array}{r}0 \\
0 \\
0 \\
1 \\
8 \\
73 \\
12 \\
57 \\
5 \\
93 \\
86 \\
79 \\
28 \\
11 \\
55 \\
78 \\
13\end{array}$ \\
\hline
\end{tabular}

*Arbitrary scoring of marrow iron: $0,++++++(-$, result not available $)$.

Though a good correlation was obtained in the whole-body counting method between the sitting and lying positions ( $r=$ $+0.994, P<0.001, n=16$ ), the estimate of absorption for the 
sitting posture was much higher than for the lying position in four patients and exceeded $100 \%$ in two.

There was a high correlation $(\mathrm{r}=+0.987, \mathrm{P}<0.001, \mathrm{n}=16)$ between percentage iron absorption measured by whole-body counting in the lying position $\left(\mathrm{y}_{1}\right)$ and the double isotope method ( $x$ ) ; these data are shown in Fig. 1. The regression equation of $y_{1}$ on $\mathrm{x}$ is given by $\mathrm{y}_{1}=1.02 \mathrm{x}-2.41$. The slope of

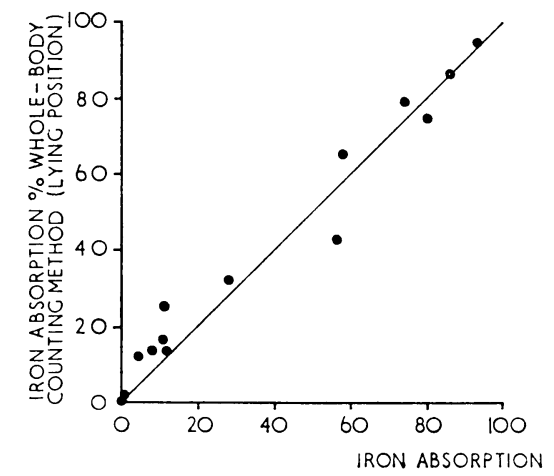

Fig. 1 of background radioactivity and a standard. The apparatus cost approximately $£ 750$, excluding the scaler.

\section{Summary}

A simple inexpensive whole-body counting technique for iron absorption in which radioactivity was measured in three posi-

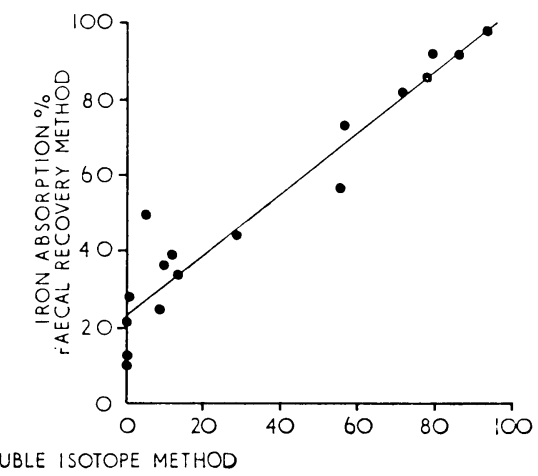

FIG. 2

FIG. 1.-Relation between iron absorption as measured by the double isotope method and the whole-body counting method (lying position). FIG. 2. -Relation between iron absorption as measured by the double isotope method and the faecal recovery method.

this is not significantly different from 1.00 and the intercept is not significantly different from zero-that is, the regression line is not significantly different from the line of identity.

The correlation $(r=+0.961, P<0.001, n=17)$ between the results of the faecal recovery method $\left(\mathrm{y}_{2}\right)$ and the double isotope method ( $\mathrm{x}$ ) was also good (Fig. 2). However, the regression equation for $y_{2}$ upon $x$ is given by $y_{2}=0.798 x+23.5$. The regression coefficient of this line is significantly different from $1.00(0.001<\mathrm{P}<0.01)$ and the intercept is significantly different from zero $(P<0.001)$. Hence this regression line differs significantly from the line of identity.

\section{Discussion}

It is shown that the whole-body counter used with couch geometry gave results in good agreement with those from the double isotope technique. The sitting position led to rather poorer agreement, presumably owing to redistribution effects.

There was considerable discrepancy between the faecal recovery method and the other two methods, especially at the lower levels of iron absorption. This difference is believed to be due to incomplete faecal collections, despite full co-operation from nursing staff and patients. A similar result was obtained by Pitcher et al. (1965). Callender et al. (1966), in comparing results obtained by the whole-body counting method and faecal recovery method, believed that stools were lost by 16 of their 54 patients.

Callender et al. (1966) concluded that a whole-body counting technique with the use of a double detector system and travelling motor-driven couch was a very reliable and convenient way of measuring iron absorption. The present study, in which a very simple whole-body counting system was employed, confirms this view. Counts made in three positions from each side of the patient are combined, and this seems to overcome inaccuracies from redistribution of isotope. Each measurement of whole-body radioactivity took about 15 minutes; a further 15 minutes was required for the counting tions with the patient prone and supine is described. It gave results which correlated well with the double isotope method in 16 patients who showed a wide range of haemoglobin level, serum iron, and stainable marrow iron.

Only two measurements on the patient were required, each taking about 15 minutes.

The faecal recovery method for iron absorption, which was used simultaneously, showed poor agreement with the wholebody counting and double isotope techniques. The discrepancy was believed to be due to incomplete stool collections, despite attempts to avoid this.

We wish to thank Dr. D. L. Gardner for estimation of marrow iron and Dr. W. N. M. Ramsay for assistance and advice and the determinations of serum iron. We are grateful to Miss A. A. McKay, Miss I. Martin, and Miss M. McArthur for their technical assistance.

Requests for reprints to be addressed to John Richmond, M.D.

\section{REFERENCES}

Callender, S. T., Witts, L. J., Warner, G. T., and Oliver, R. (1966). Brit. 7. Haemat., 12, 276 .

Dacie, J. V., and Lewis, S. M. (1963). Practical Haemato!ogy, 3rd ed London.

Dubach, R., Callender, S. T. E., and Moore, C. V. (1948). Blood, 3 526.

Pirzio-Biroli, G., Bothwell, T. H., and Finch, C. A. (1958). 7. Lab. clin Med., $51,37$.

Pitcher, C. S., Williams, H. S., Parsonson, A., and Williams, R. (1965). Brit. F. Haemat., 11, 633 .

Price, D. C., Cohn, S. H., Wasserman, L. R., Reizenstein, P. G., and Cronkite, E. P.' (1962). Blood, 20, 517.

- Reizenstein, P. G., Cohn, S. H., Cronkite, E. P., and Wasserman, L. R. (1961). Clin. Res., 9, 165 .

Ramsay, W. N. M. (1957). Clin. chim. Acta, 2, 214.

Richmond, J., Gardner, D. L., Roy, L. M. H., and Duthie, J. J. R. (1956). Ann. rheum. Dis., 15, 217.

Saylor, L., and Finch, C. A. (1953). Amer. F. Physiol., 172, 372.

Schiffer, L. M., Price, D. C., Cultner, J., Cohn, S. H., and Cronkite, E. P. (1964). Blood, 23, 757 .

van Hoek, R., and Conrad, M. E. (1961). F. clin. Invest., 40, 1153.

Veall, N., and Vetter, H. (1958). Radioisotope Techniqués in Clinical Research and Diagnosis. London. 